\title{
Sediment traps from synthetic construction site stormwater runoff by grassed filter strip
}

\begin{abstract}
Sediment trapping of the synthetic construction site stormwater runoff (SCSSR) by grassed filter strip (GFS) was studied in a laboratory flume with simulated GFS of different slopes and bed surface areas. The polynomial regression model of average rainfall density depended rainfall duration has been approved by Malaysian Storm Water Management Manual. Still the relationship between either stormwater runoff flow rate or sediment trapping efficiency and rainfall duration needs to be verified. This study proposes the use of the empirical equations to determine the SCSSR flow rate and to estimate the efficiency of the GFS models to trap sediment based on the rainfall duration. All the parameters in equations have physical meanings, and experimental data validation showed that the equations are sufficiently accurate. The stormwater runoff flow rate and efficiency of the GFS models were verified for the SCSSR originally coming from a construction site of Kuala Lumpur city. New approaches to investigate the hydrological behaviour of construction site are presented and have significant implications for the ability of stormwater flow to carry sediment.
\end{abstract}

Keyword: Construction site; Empirical model; Grassed filter strip; Sediment particles; Sediment traps; Synthetic stormwater runoff 